\title{
Early Urological Complications After Live Related Renal Transplantation: An Update
}

\author{
Hossain TMS ${ }^{1}$, Karim $\mathrm{T}^{2}$ \\ ${ }^{1}$ Department of Urology, Bangabandhu Sheikh Mujib Medical University, Dhaka, Bangladesh, ${ }^{2}$ Department of \\ Paediatric Cardiology, Bangabandhu Sheikh Mujib Medical University, Dhaka, Bangladesh
}

\begin{abstract}
Background: Kidney transplant is the standard of care for end stage kidney disease and associated with immunological, vascular and urological complications. Urological complications remain the most common type of surgical complication in the early post-transplant period, inspite of major procedural advances many grafts are still being lost due to same.
\end{abstract}

Objectives: The purpose of this review was to discuss the different presentations, compare various ureterovesical anastomosis techniques and provide a basic overview for the management of post-transplant urological complications hence to improve graft and patient survival.

Methods: This study was a narrative review. Recent available literature was searched by keywords. The most recent information from relevant articles were collected and reviewed. This write up was compiled after the review of articles from the last 50 years.

Results: Majority of these complications could be traced back to the time of retrieval and anastomosis of ureter. So, the high degree of suspicion, early detection, accurate diagnosis and timely management of urological complications occurring after kidney transplant were the key tasks of transplant team managing the patients. A delay in diagnosis or management of these complications could lead to morbidity to the recipient even graft loss and or mortality.

Conclusion: To minimize the early complications of post kidney transplantation high degree of suspicion and prompt intervention is needed for graft and patient survival.

Keywords: Live related renal transplant, Early urological complications, Urine leak, Ureteroneocystostomy

\section{Introduction}

Kidney transplantation remains the best renal replacement option for most patients of end stage kidney diseases. ${ }^{1}$ Despite of refinements in surgical technique it is not devoid of complications. Urological complications have been seen since the earlier days of Renal Transplantation and causing significant morbidity and even mortality. In the early days the reported incidence of urological complications in between $10 \%$ and $25 \%$ with an associated mortality 20 $30 \% .^{2-5}$ The incidence has decreased significantly over the past 40 years with advancement of surgical procedures and improvement of suture materials and current reports it declines to $2.8 \%$ and $15.5 \%{ }^{6,7}$ A review of literature indicates that there are many different techniques for ureteroneocystostomy, in addition, some centres use DJ ureteral stent routinely while others use selectively and some other do not use at all.

*Correspondence: Dr. Tohid Mohammad Saiful Hossain, Department of Urology, Bangabandhu Sheikh Mujib Medical University, Dhaka, Bangladesh; email:dr.tmsh@yahoo.com.ORCID:0000-0002-4856-3625
Still number of renal allografts are lost due to urological complications especially in early posttransplant period (within 90 days). ${ }^{8}$

The purpose of this review was to discuss different presentations and provide an evidence-based management plan for recipients who present with such complications in early post-transplant period.

Operative Procedure: A detailed operative description for kidney transplant was not the purpose of this review. However, a basic understanding of the procedure and the regional anatomy is necessary for better understand the possible complications.

The surgical technique for kidney transplant has changed very little from the original pelvic operation described in 1951 by Kuss et all. ${ }^{9}$ The most common operation in now a days extra peritoneal right iliac fossa because it allows early access of future graft biopsy and on the right side the more superficial location of the iliac vein. However, the left iliac fossa may be used when there is previous history of transplant or significant arterial disease on the right side or recipient is the candidate for future pancreas 
transplant. Another option is to place the kidney in an intra-abdominal position through the midline position when a recipient had history of both iliac fossa transplant, in paediatric renal transplant or option is useful when a pancreas transplant is being performed simultaneously.

With the standard pelvic operation the dissection is extra peritoneal, the renal vein is anastomoses with external iliac vein in end to side and the renal artery is anastomosed with external iliac early in end to side fashion or with internal iliac artery in end to end fashion. To minimize the risk of lymphocele formation only a modest length of artery is dissected free and the lymphatics overlying the artery are cauterized or ligated.

Urinary continuity can be restored by a number of different techniques - The most common technique are posterior leadbetter politano or Lich Gregoir technique. Regardless the technique used the anastomosis must be tension free, water light, well vascularized and protected by at least a $1 \mathrm{~cm}$ submucosal tunnel.

Outline of early urological complications: The incidence of urological complications following kidney transplantation as described in early studies (i.e. including patients between 1970-1990s) ranged between $4.2 \% \%$ to $14.1 \%(10-14)$, while in later studies (i.e including patients between 1990-2000) it ranged between 3.7-6.0\%. ${ }^{15-17}$

The reported early urological complications are perurethral catheter related problems like block leads to retention, peri catheter leakage, hematuria, peri transplant fluid collection, urinary leaks and or obstruction urine leaks can result in the formation of urinomas. These collections can compress vascular structure or urine outflow causing graft dysfunction. ${ }^{18,19}$ In addition, urine leaks are associated with increased risk of surgical site infection which can lead to perinephric abscess. ${ }^{20,21}$

Ultrasonography is the first line imaging modality for graft evaluation in immediate post-transplant period, especially when suspecting vascular problems, fluid collections and or obstruction, it can also give additional information on graft function by measuring the intrarenal resistivity indices. ${ }^{22-24}$ Differentiating between different types of collection on ultrasound can be difficult. A urinoma usually appears as a welldefined, rapidly enlarging non-echoic fluid collection without septations, lymphoceles are hypoechoic to anechoic, occasionally with internal septa and debris whereas a hematoma usually has a complex and echogenic appearance with numerous septation. ${ }^{22-25}$ CT scan many assist in the diagnosis by further elucidating the ultrasound findings such as the extent or exact relationship of the fluid collection to the transplant kidney. ${ }^{23} 99^{\mathrm{m} T C}$, MAG-3 radionuclide isotope scan is useful to confirm the presence of urine leak outside the anatomical space of urinary tract. ${ }^{26}$

A cystogram can provide additional information to establish the exact site of urine leak. Particularly if it is at the ureterovesical junction. Antegrade pyelography through nephrostomy tube remains the investigation of choice to identify the exact size and extent of urine leak and also the site of obstruction. Ultrasound and or CT guided needle aspiration followed by biochemical and bacteriological analysis is essential in diagnosing the exact etiology of fluid collections. ${ }^{18}$ A fluid creatinine above the serum level indicates a urine leak as opposed to a lymphocele which has levels similar to that of serum. Gram stain and Cultures are important to find out any infection. ${ }^{20}$

Presentation and management of urological complications (early):

1. Per urethral catheter related: Immediate postoperative period catheter drainage may blocked by hardens of jelly, small blood clot which can be managed by simple milking of catheter or flush by water, may need change of catheter. For some reason catheter may placed beneath the high and get compressed or kinked, so take it above the high and fixed it at the thigh. Sometimes peri catheter leakage is seen, that is probably due to trigonal irritation of catheter balloon, so fix the catheter above the thigh and antimuscarinic may help.

2. Hematuria: Mild hematuria is not uncommon. It is usually observed in the first 12-24 hours after transplant which resolves spontaneously in most cases. More extensive bleeding may results in retained blood clots and urinary tract obstruction, which may be the cause of sudden caseation of urine output. Continuous bladder irrigation will usually restore output if not cystoscopic evacuation of clot may be necessary.

3. Urine leaks: Urine leaks usually present in immediate or early post-operative period (3 month). ${ }^{27}$ Presentation includes pain and swelling in the transplant area, rising creatinine. Oliguria, and or signs of systemic infection. ${ }^{28}$ In the immediate post-transplant period urine leaks can manifest via the drains or through the wound leading to delayed healing and increased risk of infection. ${ }^{29}$ In addition, leaking urine can translocate in the 
retroperitoneal space, pelvis and occasionally in the presacral and scrotal region. ${ }^{30}$ The leaking of infected urine could lead to perinephric infections and abscess. Most urological complications can be traced back to technical errors during retrieval, bench dissection or implantation. ${ }^{29}$ The majority of leaks occur at the distal portion of the ureter most commonly at the site of ureteroneocystostomy. ${ }^{27}$ Distal ureteral ischemia and necrosis secondary to compromised blood supply is thought to be the main factor for early ureteral complications in most patients in the absence of technical difficulties during transplant operation. ${ }^{31}$ In contrast to native ureters which derive their blood supply via both renal arteries and pelvic collateral, the transplanted ureter depends solely on branches of renal artery that passes in peri ureteric tissue. It may be believe that gentle handling of the ureter and peri ureteric tissue and keeping the length of the ureter as short as possible without tension is of key importance.

The ureterovesical anastomosis associated with lowest rate of complications is a subject of debate. In a recent meta-analysis which included two randomized control studies and 24 observational studies, the Lich-Gregior technique was found to significantly reduce the incidence of ureteral leaks which compared to the leadbetter politano and Taguchi techniques. ${ }^{32}$ Currently many centers adopted the routine use of ureteric stent during kidney transplant. A meta-analysis which included seven randomized controlled studies confirmed that prophylactic $\mathrm{JJ}$ stenting is well tolerated and reduces major urological complications. ${ }^{33}$ Despite some opposition due to the higher incidence of urinary tract infection, current evidence recommends the routine use of prophylactic JJ stenting.

Management of urine leaks either conservative or reconstructive depending on the site, cause and extent of the leak. Transplant surgeons should keep in mind that the treatment strategies are not based on robust scientific evidence and may very between centres. The current best available evidence is based on retrospective studies, a conservative approach usually involves insertion of percutaneous nephrostomy followed by antegrade stenting together with a foley catheter replacement. Retrograde JJ stenting of transplant ureter is technically demanding and often impossible due to atypical position of neoureteric orifice. This procedure diverts the urine flow away from the leaking site and fully decompresses the colleting system in order to allow for healing to take place. Foley catheter is removed once the leak has resolved and many centres report stent deployment for a period of 612 weeks. $^{34,35}$

Surgical exploration is required if the urine leak fails to resolve following maximal decompression. During the surgical procedure, the necrotic ureter should be resected proximally until healthy tissue is found, followed by reimplantation. If the remaining viable ureter is short an ipsilateral ureteroureterostomy, pyeloureterostomy, pyelovesicostomy, psoashitch, boariflap, or fashioning an ileal ureter are alternative techniques that could be done for tension free anastomosis. ${ }^{36}$ Traditionally, urine leaks have been corrected by open surgical reconstruction, over the last two decades advances in interventional radiology have allowed several patients to be managed by percutaneously. This conservative approach has been shown to be successful in a number of retrospective studies, with a success rate varying between $30 \%$ and $87 \% .^{15,17,37-41}$ We believe that outcome largely depends on the etiology, site and extent of urine leak and early intervention is the key to prevent graft loss and even morbidity and mortality. Surgical reconstruction is usually successful in the majority of cases. ${ }^{15,17}$ Moreover, some patients required more than one surgical procedure for complete resolution.

4. Obstruction: Early obstruction may be due to edema, blood clots, hematoma, peri transplant fluid collection and kinking. Presentation is usually with elevated serum creatinine level, which must be differentiated from other surgical and non-surgical causes of early graft dysfunction. Ultrasounogram and furosemide renogram is useful tool for diagnosis. Antegrade study is the most specific test to see the level of obstruction and percutaneous nephrostomy is obliviously helpful for decompression and or internal/external JJ stenting may help. If such approach is not successful the surgical intervention is indicated. $^{42}$

\section{Limitations}

This narrative update aimed to provide a gross overview of the early urological complications after live related kidney transplantation. Here, it was performed extensive literature search but the selected articles have not been subjected to quality evaluation. 


\section{Conclusion}

Among the early post kidney transplant urological complications urine leaks remain the most common and challenging. High degree of suspicion for diagnosis and early management is the key to prevent significant morbidity and graft loss and even occasional mortality. Preservation of peri ureteric tissue during donor kidney retrieval, LichGregoir uretero-neocystostomy technique, routine prophylactic ureteral stenting has been associated with lower incidence of such complications.

\section{Conflict of interest: None}

Funding: None

Submitted: $30^{\text {th }}$ June, 2020

Final revision received: $26^{\text {th }}$ July, 2020

Accepted: $30^{\text {th }}$ July, 2020

Published: $1^{\text {st }}$ August, 2020

\section{References}

1. Wolfe RA, Ashby VB, Milford EL, Ojo AO, Ettenger RE, Agodoa LY,Held PJ, Port FK. Comparison of mortality in all patients on dialysis,patients on dialysis awaiting transplantation, and recipients of a firstcadaveric transplant. N Engl J Med 1999; 341: 1725-1730. DOI: 10.1056/NEJM199912023412303

2. Starzl TE,Groth CG, Putnam CW, et al. Urological com-plications in 216 human recipients of renal transplant. Ann Surg. 1970; 172:1e22.

3. Loughlin KR, Tilney NL, Richie JP. Urologic complicationsin 718 renal transplantpatients. Surgery. 1984;95:297e302.

4. Colfry AJ, Schlegel JU, Lindsey ES, et al. Urological com-plications in renal transplantation. J Urol. 1974; 112:564e6.

5. Mundy AR, Podesta ML, Bewick M, et al. The urologicalcomplications of 1000 renal transplants. Br J Urol. 1981; 53:397e402.

6. Davari HR, Yarmohammadi H, Malekhosseini SA, et al.Urological complications in 980 consecutive patients with renaltransplantation. Int J Urol. 2006; 13:1271e5.

7. Praz V,Leisinger HJ, Pascual M, Jichlinski P. Urologicalcomplications in renal transplantation from cadaveric donor grafts: a retrospective analysis of 20 years. Urol Int. 2005; 75: 144e9.

8. Wojciech K, Janusz D, Anna K, Bartosz M, Krzysztof T, Michał M, Paweł C, Maria B, Marian $\mathrm{K}$, Romuald Z. Urological complications after renal transplantation - a single centre experience. Cent European J Urol. 2016; 69: 306-311.

DOI: $10.5173 /$ ceju.2016.833

9. Abhinav Humar, Arthur J. Matas Surgical Complications After Kidney Transplantation. Seminars in Dialysis. 2005; 18: 505-10.

10. Streeter EH, Little DM, Cranston DW, Morris PJ. The urologicalcomplications of renal transplantation: a series of 1535 patients. BJU Int. 2002; 90: 627-34.

DOI: $10.1046 /$ j. 1464-410X.2002.03004.x

11. Jaskowski A, Jones RM, Murie JA, Morris PJ. Urologicalcomplications in 600 consecutive renal transplants. Br J Surg. 1987;74: 922-25.

DOI: $10.1002 /$ bjs. 1800741015

12. Loughlin KR, Tilney NL, Richie JP. Urologic complications in 718renal transplant patients. Surgery. 1984; 95: 297-302.

PMID: 6367124

13. Rigg KM, Proud G, Taylor RM. Urological complications followingrenal transplantation. A study of 1016 consecutive transplants froma single centre. Transpl Int. 1994; 7: 120-26 DOI:10.1111/j.1432-2277.1994.tb01231.x

14. Mäkisalo H, Eklund B, Salmela K, Isoniemi H, Kyllönen L,Höckerstedt K, Halme L, Ahonen J. Urological complications after2084 consecutive kidney transplantations. Transplant Proc. 1997; 29:152-53

DOI: 10.1016/S0041-1345(96)00044-9

15. Buresley S, Samhan M, Moniri S, Codaj J, Al-Mousawi M. Postrenaltransplantation urologic complications. Transplant Proc. 2008; 40:2345-2346 DOI: $10.1016 /$ j.transproceed.2008.06.036

16. Yigit B,Tellioglu G, Berber I, Aydin C, Kara M, Yanaral F, Titiz I.Surgical treatment of urologic complications after renal transplantation. Transplant Proc. 2008; 40: 202-04.

DOI: $10.1016 /$ j.transproceed.2007.11.024

17. Samhan M, Al-Mousawi M, Hayati H, Abdulhalim M, Nampoory MR. Urologic complications after renal transplantation. Transplant Proc. 2005; 37: 3075-76.

DOI: 10.1016/j.transproceed.2005.07.047

18. Humar A, Matas AJ. Surgical complications after kidneytransplantation. Semin Dial. 2005; 18:505-10 DOI: 10.1111/j.1525-139X.2005.00097.x

19. Haberal M,Boyvat F, Akdur A, Kırnap M, Özçelik Ü, YarbuğKarakayalı F. Surgical Complications After Kidney Transplantation. Exp Clin Transplant. 2016; 14: 587-595.

PMID: 27934557

20. Rao PS, Ravindran A, Elsamaloty H, Modi KS. Emphysematousurinoma in a renal transplant patient. Am J Kidney Dis. 2001; 38: E29

DOI: $10.1053 /$ ajkd.2001.28626

21. Capocasale E, De Vecchi E, Mazzoni MP, Dalla Valle R, Pellegrino C, Ferretti S, Sianesi M, Iaria M. Surgical site and early urinary tractinfections in 1000 kidney transplants with antimicrobial perioperativeprophylaxis. Transplant Proc. 2014; 46: 3455-58.

DOI: $10.1016 /$ j.transproceed.2014.07.071

22. Kolofousi C,Stefanidis K, Cokkinos DD, Karakitsos D, Antypa E,Piperopoulos P. Ultrasonographic 
features of kidney transplants andtheir complications: an imaging review. ISRN Radiol. 2012; 2013:480862.

DOI:10.5402/2013/480862

23. Vernuccio F,Gondalia R, Churchill S, Bashir MR, Marin D. CTevaluation of the renal donor and recipient. Abdom Radiol. (NY) 2018. DOI: $10.1007 / \mathrm{s} 00261-018-1508-1$

24. Schwarz C, Mühlbacher J, Böhmig GA, Purtic M, Pablik E, UngerL, Kristo I, Soliman T, Berlakovich GA. Impact of ultrasoundexamination shortly after kidney transplantation. Eur Surg. 2017; 49:140-144. DOI: $10.1007 / \mathrm{s} 10353-017-0467-\mathrm{z}$

25. Park SB, Kim JK, Cho KS. Complications of renal transplantation:ultrasonographic evaluation. J Ultrasound Med. 2007; 26: 615-33.

DOI: $10.7863 /$ jum.2007.26.5.615

26. Irshad A, Ackerman S, Sosnouski D, Anis M, Chavin $\mathrm{K}$, Baliga P. Areview of sonographic evaluation of renal transplant complications. Curr Probl Diagn Radiol. 2008; 37: 67-79.

DOI:10.1067/j.cpradiol.2007.06.001

27. Kumar A, Verma BS, Srivastava A, Bhandari M, Gupta A, SharmaR. Evaluation of the urological complications of living related renaltransplantation at a single center during the last 10 years: impact of theDouble-J* stent. J Urol. 2000; 164: 657-60. DOI:10.1016/S0022-5347(05)67275-8

28. Sabnis RB, Singh AG, Ganpule AP, Chhabra JS, Tak GR, Shah JH.The development and current status of minimally invasive surgery tomanage urological complications after renal transplantation. Indian $\mathrm{J}$ Urol. 2016; 32: 186-91.

DOI: $10.4103 / 0970-1591.185100$

29. Hamouda M, Sharma A, Halawa A. Urine Leak After Kidney Transplant: A Review of the Literature. Exp Clin Transplant. 2018; 16:90-95.

PMID: 29409437

30. Son H,Heiba S, Kostakoglu L, Machac J. Extraperitoneal urine leakafter renal transplantation: the role of radionuclide imaging and the value of accompanying SPECT/CT - a case report. BMC Med Imaging. 2010; 10: 23.

DOI: $10.1186 / 1471-2342-10-23$

31. Karam G,Maillet F, Parant S, Soulillou JP, GiralClasse M. Ureteralnecrosis after kidney transplantation: risk factors and impact on graftand patient survival. Transplantation. 2004; 78: 725-29. DOI: 10.1097/01.TP.0000131953.13414.99

32. Alberts VP, Idu MM, Legemate DA, Laguna Pes MP, Minnee RC. Ureterovesical anastomotic techniques for kidney transplantation: asystematic review and metaanalysis. Transpl Int. 2014; 27: 593-605.
DOI: $10.1111 /$ tri.12301

33. Wilson $\mathrm{CH}$, Rix DA, Manas DM. Routine intraoperative uretericstenting for kidney transplant recipients. Cochrane Database Syst Rev. 2013; CD004925

DOI: 10.1002/14651858.CD004925.pub3

34. Wilson CH, Rix DA, Manas DM. Routine intraoperative uretericstenting for kidney transplant recipients. Cochrane Database Syst Rev. 2013: CD004925

DOI: 10.1002/14651858.CD004925.pub3

35. Dinckan A,Tekin A, Turkyilmaz S, Kocak H, Gurkan A,Erdogan O, Tuncer M, Demirbas A. Early and late urologicalcomplications corrected surgically following renal transplantation. Transpl Int. 2007; 20: 702-707.

DOI: $10.1111 / \mathrm{j} .1432-2277.2007 .00500 . x$

36. Charlesworth M, Marangoni G, Ahmad N. High ureteric injuryfollowing multiorgan recovery: successful kidney transplant withBoari flap ureterocystostomy reconstruction. Arab J Nephrol Transplant. 2011; 4: 155-158. DOI: 10.4314/ajnt.v4i3.71028

37. Shokeir AA, Shamaa MA, Bakr MA, el-Diasty TA, Ghoneim MA.Salvage of difficult transplant urinary fistulae by ileal substitution ofthe ureter. Scand J Urol Nephrol.1993; 27: 537-540 DOI: $10.3109 / 00365599309182291$

38. Iezzi R, la Torre MF, Santoro M, Dattesi R, Nestola M, Posa A, Romagnoli J, Citterio F, Bonomo L. Interventional radiological treatmentof renal transplant complications: a pictorial review. Korean J Radiol. 2015; 16: 593-603. DOI: $10.3348 / \mathrm{kjr} .2015 .16 .3 .593$

39. Matalon TA, Thompson MJ, Patel SK, Ramos MV, Jensik SC, MerkelFK. Percutaneous treatment of urine leaks in renal transplantationpatients. Radiology. 1990; 174: 1049-1051. DOI:10.1148/radiology.174.3.174-3-1049

40. Campbell SC, Streem SB, Zelch M, Hodge E, Novick AC. Percutaneous management of transplant ureteral fistulas: patientselection and long-term results. J Urol1993; 150: 1115-1117. DOI: 10.1016/S0022-5347(17)35701-4

41. Alcaraz A, Bujons A, Pascual X, Juaneda B, Martí J, de la Torre P, Guirado L, Díaz JM, Ribal MJ, Solá $\mathrm{R}$, Villavicencio H. Percutaneousmanagement of transplant ureteral fistulae is feasible in selectedcases. Transplant Proc. 2005; 37: 2111-14. DOI: 10.1016/j.transproceed.2005.03.118

42. Rosenthal JT: Surgical management of urological complications after kidney transplantation. Semin Urol. 199412:114-22. 